\title{
DESIGN OF V-SLOTTED MICROSTRIP PATCH ANTENNA FOR YIELDING IMPROVED GAIN BANDWIDTH PRODUCT
}

\author{
Chandan Bangera ${ }^{1}$, Manjusha Joshi ${ }^{2}$ \\ ${ }^{1}$ MTech Student, EXTC, MPSTME NMIMS, Maharashtra, India \\ ${ }^{2}$ Assistant Professor, EXTC, MPSTME NMIMS, Maharashtra, India
}

\begin{abstract}
In this paper, a novel antenna design for improvement of patch antenna gain and bandwidth has been proposed.The proposed antenna design is a V-slotted rectangular microstrip patch antenna for yielding improved gain bandwidth product suitable for WLAN and Wi-Max applications. The antenna operates at $5.9 \mathrm{GHz}$ and has the maximum achievable bandwidth obtained about $1.04 \mathrm{Ghz}$ and gain of 6.22dBi. The microstrip patch is constructed using a single layer RT/duroid (5880) substrate, having dielectric constant $\varepsilon r=2.2$ and loss tangent tan $\delta=0.001$.A co-axial feed is used and the antenna is simulated using IE3D software from Zeland based on method of moments.
\end{abstract}

Key Words: RMSA, V-slot, Gain-Bandwidth product, WLAN, Wi-Fi.

\section{INTRODUCTION}

In this era of next generation networks the need for high data rates and small size of devices has been increased tremendously. In this evolution two important standards are Wi-Fi (WLAN) and Wi-MAX. For success of all these wireless applications efficient robust antennas are essential. The study on microstrip patch antennas has made a great progress and impact in the recent years. Compared with the conventional antennas, microstrip patch antennas have more advantages and better prospects [1]. Microstrip antennas (MSA) have characteristics like low cost and mechanically robust which proves microstrip antennas (MSA) to be well suited for WLAN/Wi MAX application systems.

With the ever-increasing need for wireless and mobile communication and the emergence of many systems, it is important to design broadband antennas to cover a wide frequency range. The design of an efficient wide band small size antenna, for recent wireless applications, is a major challenge [2]. Microstrip patch antennas have found extensive application in wireless communication system owing to their advantages such as low-profile, conformability, low-cost fabrication and ease of integration with feed networks. However, conventional microstrip patch antenna suffers from very narrow bandwidth.

Various approaches have been taken to suit the need of wireless communication applications including modification of substrate parameters and the patch shape. There are certain techniques to increase the bandwidth of antennas which include increase of the substrate thickness, the use of a low dielectric substrate, the use of various impedance matching and feeding techniques, the use of multiple resonators, and the use of slot antenna geometry. A thick dielectric substrate having a low dielectric constant is desirable since this provides better efficiency, larger bandwidth and better radiation. However, such a configuration leads to a larger antenna size. In order to design a compact microstrip patch antenna, substrate with higher dielectric constants must be used which are less efficient and result in narrower bandwidth. Hence a trade-off must be realized between the antenna dimensions and antenna performance [3].

In this paper a rectangular microstrip patch antenna having a total area $344 \mathrm{~mm}^{2}$ cut into a V-slotted patch with reduced total radiating area $329 \mathrm{~mm}^{2}$ has been proposed.Three $\mathrm{V}$ slots have been cut into the patch which yields a constant gain bandwidth product.Experimental geometry of the antenna and the simulated results are presented and discussed.

\section{MATHEMATICAL ANALYSIS}

To design a rectangular microstrip patch antenna following parameters such as dielectric constant (\&r), resonant frequency (fr), and height of the substrate (h) should be considered for calculating the length and the width of the patch [4].

Width of patch (W)

$$
W=\frac{c}{2 f_{0} \sqrt{\frac{\varepsilon_{r}+1}{2}}}
$$

Effective dielectric constant of antenna is

$$
\varepsilon_{\text {reff }}=\frac{s_{r}+1}{2}+\frac{s_{r}-1}{2}\left[1+12 \frac{h}{w}\right]^{\frac{-1}{2}}
$$


Effective dielectric length of antenna is

$$
L_{e f f}=\frac{c}{2 f_{0 \sqrt{s_{r e f f}}}}
$$

The extended length $(\Delta \mathrm{L})$ of antenna is

$$
\Delta L=0.421 h \frac{\left(s_{\text {reff }}+0.3\right)\left(\frac{W}{h}+0.264\right)}{\left(\epsilon_{\text {reff }-0.258)}\right)\left(\frac{W}{h}+0.8\right)}
$$

The length is

$$
L=L_{\text {eff }}-2 \Delta L
$$

\section{ANTENNA DESIGN}

The antenna design is shown in Fig-1 proposed V-Slotted rectangular microstrip patch antenna having dimension length $(\mathrm{L})=17.2 \mathrm{~mm}$, width $(\mathrm{W})=20 \mathrm{~mm}$, and thickness $(\mathrm{h})=$ $3.2 \mathrm{~mm}$. The substrate of the patch is RT/duroid having dielectric constant $=2.2[5]$. The patch is cut into a three V slot pattern having dimensions D1 $=5 \mathrm{~mm}, \mathrm{D} 2=0.5 \mathrm{~mm}$. The patch is provided with a coaxial feed.

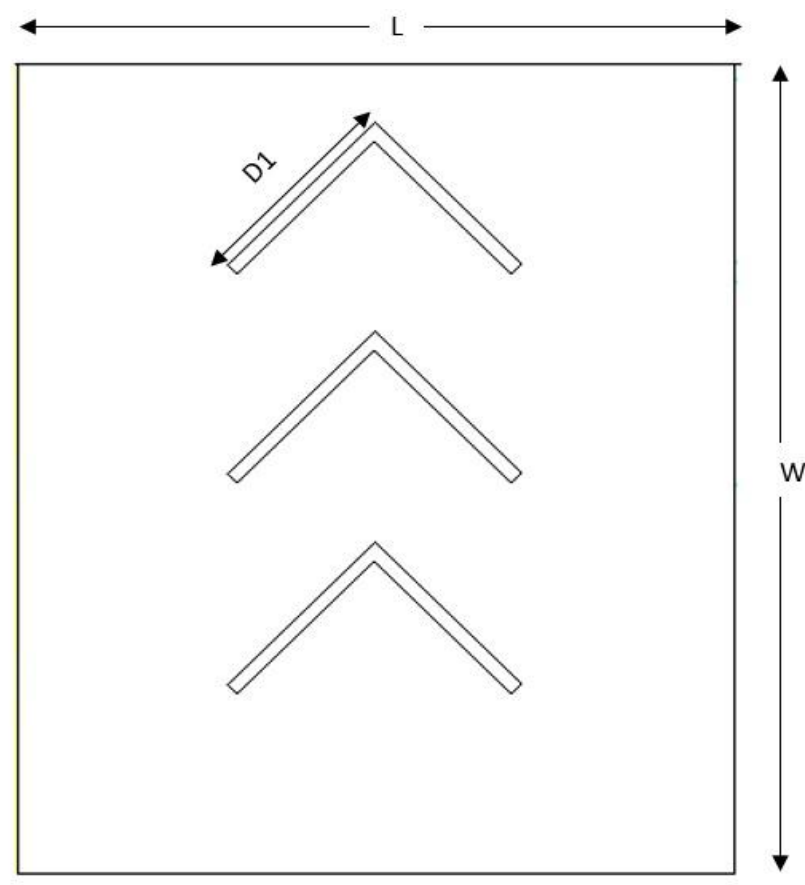

Fig -1: Geometry of the proposed antenna

Table -1: Optimized Antenna Parameters

\begin{tabular}{|l|l|}
\hline Antenna Parameter & Value \\
\hline Dielectric constant & 2.2 \\
\hline Thickness(h) & $3.2 \mathrm{~mm}$ \\
\hline Length(L) & $17.2 \mathrm{~mm}$ \\
\hline Width(W) & $20 \mathrm{~mm}$ \\
\hline Cut width D1 & $5 \mathrm{~mm}$ \\
\hline Cut length D2 & $0.5 \mathrm{~mm}$ \\
\hline
\end{tabular}

\section{RESULT AND DISCUSSION}

The antenna designed is operable at dual band frequencies 4.6 GHz and 5.2 GHz. The simulations are done using IE3D simulator from Zeland.

\subsection{Smith Chart}

$-\Gamma: s(\mathbf{1}, \mathbf{1})$

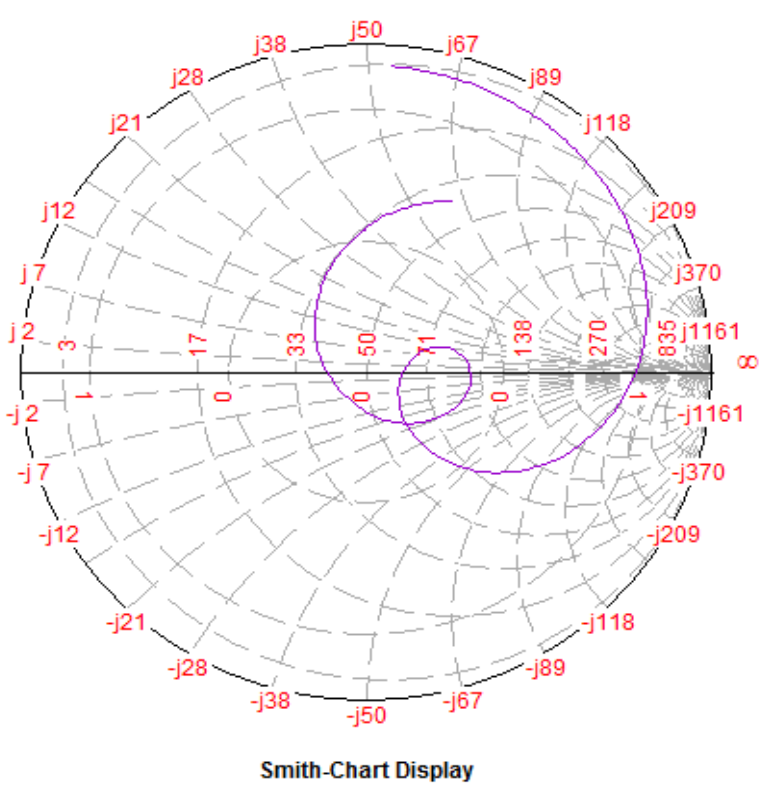

Fig -2: Smith Chart

\subsection{Return Loss Measurement}

S-Parameters Display

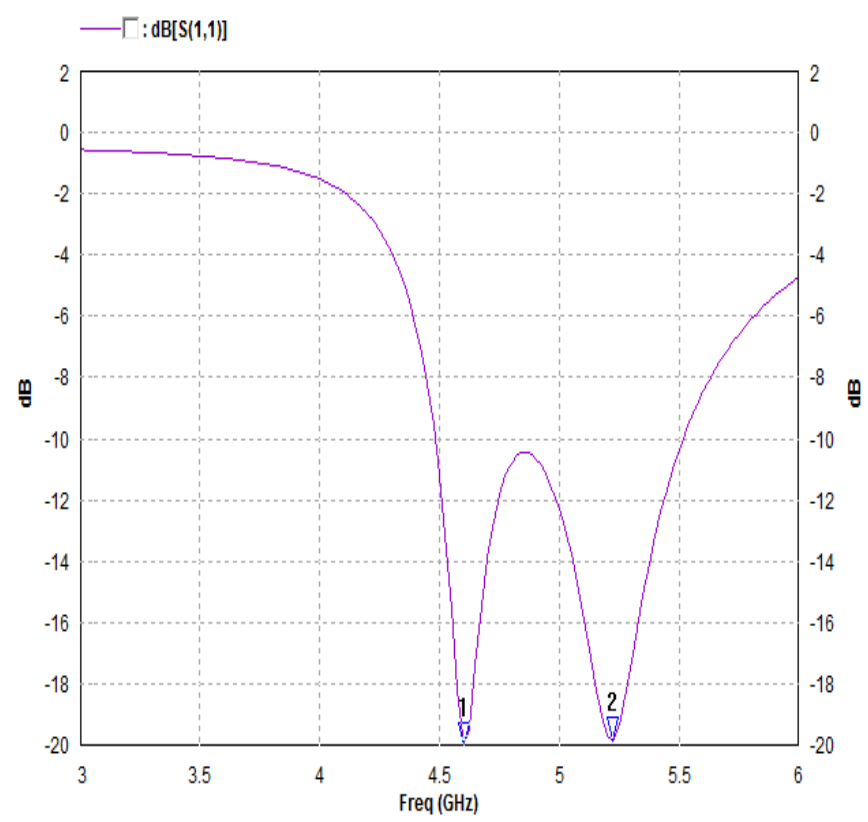

Fig -3: Return Loss v/s Frequency

Return loss $=-20 \mathrm{~dB}$ at $4.6 \mathrm{GHz}$

Return loss $=-20 \mathrm{~dB}$ at $5.2 \mathrm{GHz}$ 


\subsection{VSWR Measurement}

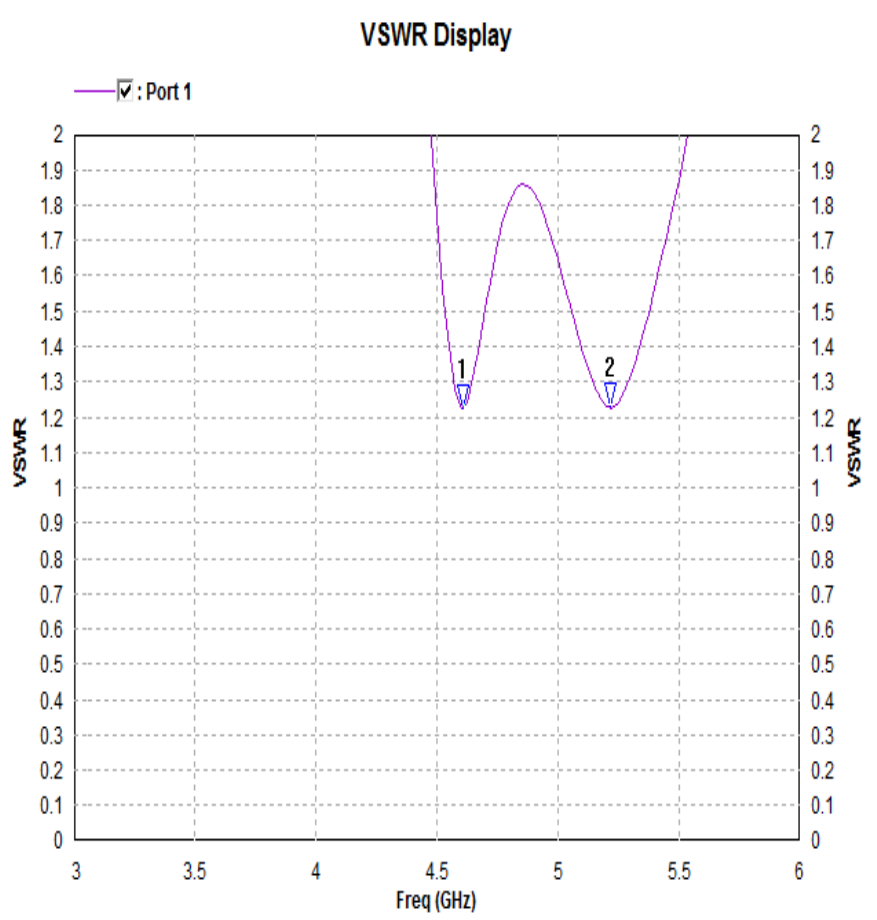

Fig -4: VSWR v/s Frequency

VSWR $=1.22$ at $4.6 \mathrm{GHz}$.

VSWR $=1.22$ at $5.2 \mathrm{GHz}$

\subsection{Axial Ratio}

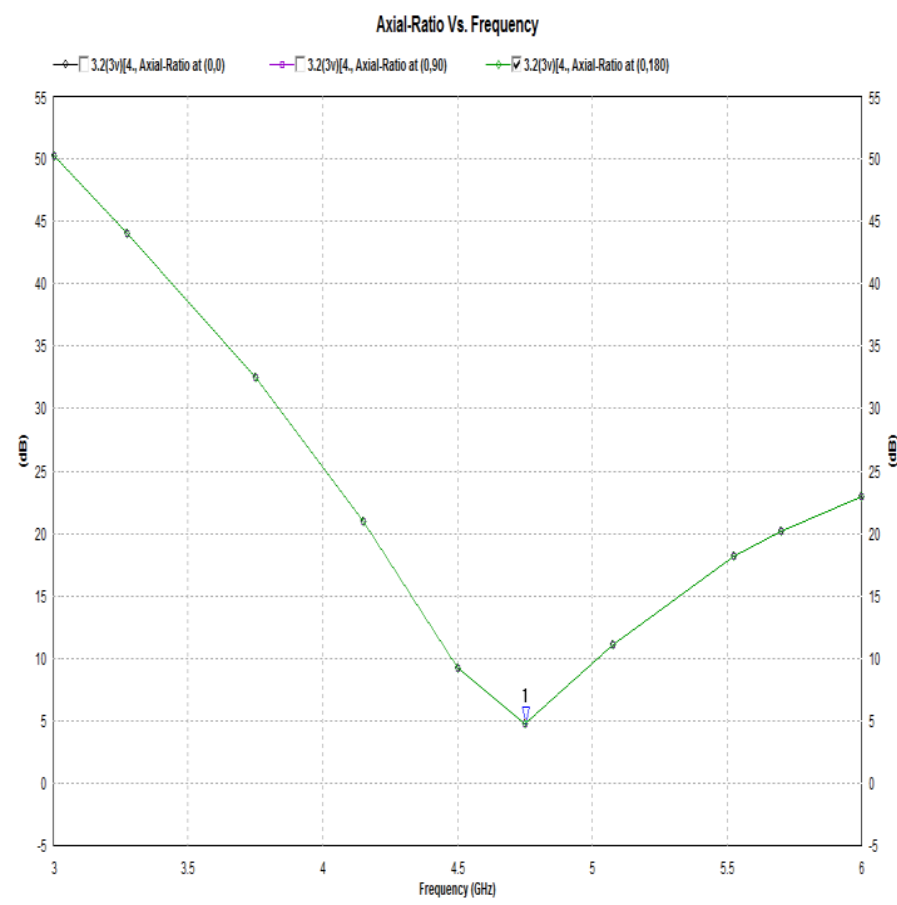

Fig -5: Axial ratio v/s Frequency

Axial ratio $=4.76 \mathrm{dBi}$ at $4.74 \mathrm{GHz}$

\subsection{Gain}

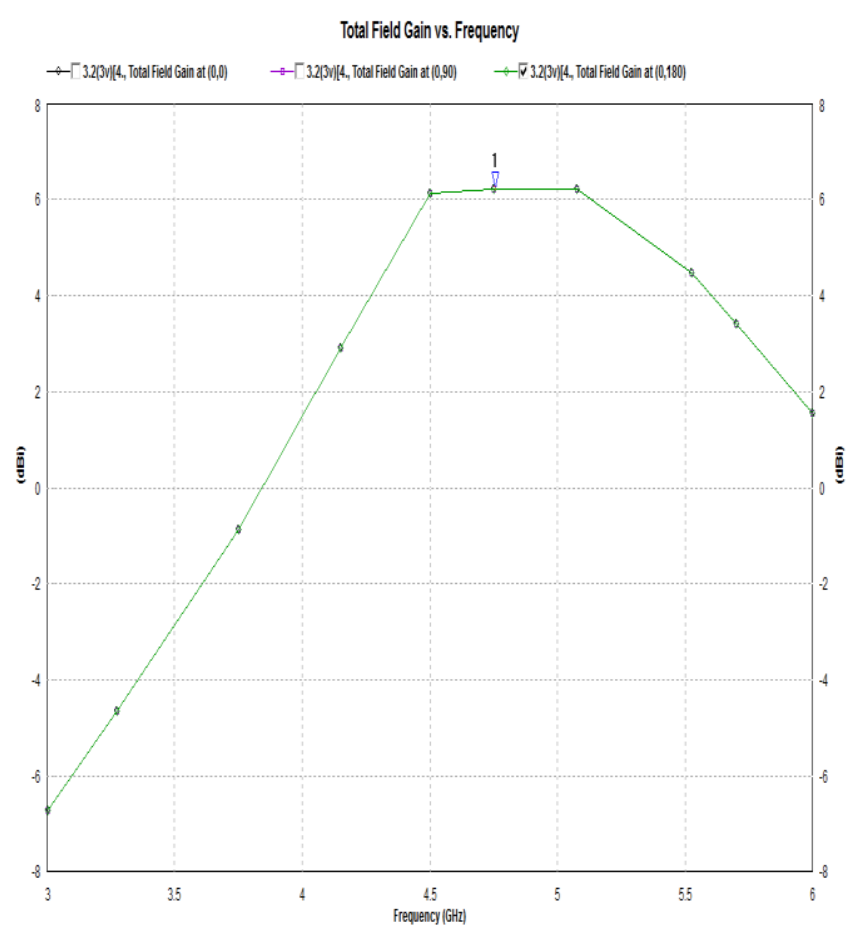

Fig -6: Total gain v/s Frequency

Gain $=6.22 \mathrm{dBi}$ at $4.74 \mathrm{GHz}$

\subsection{Directivity}

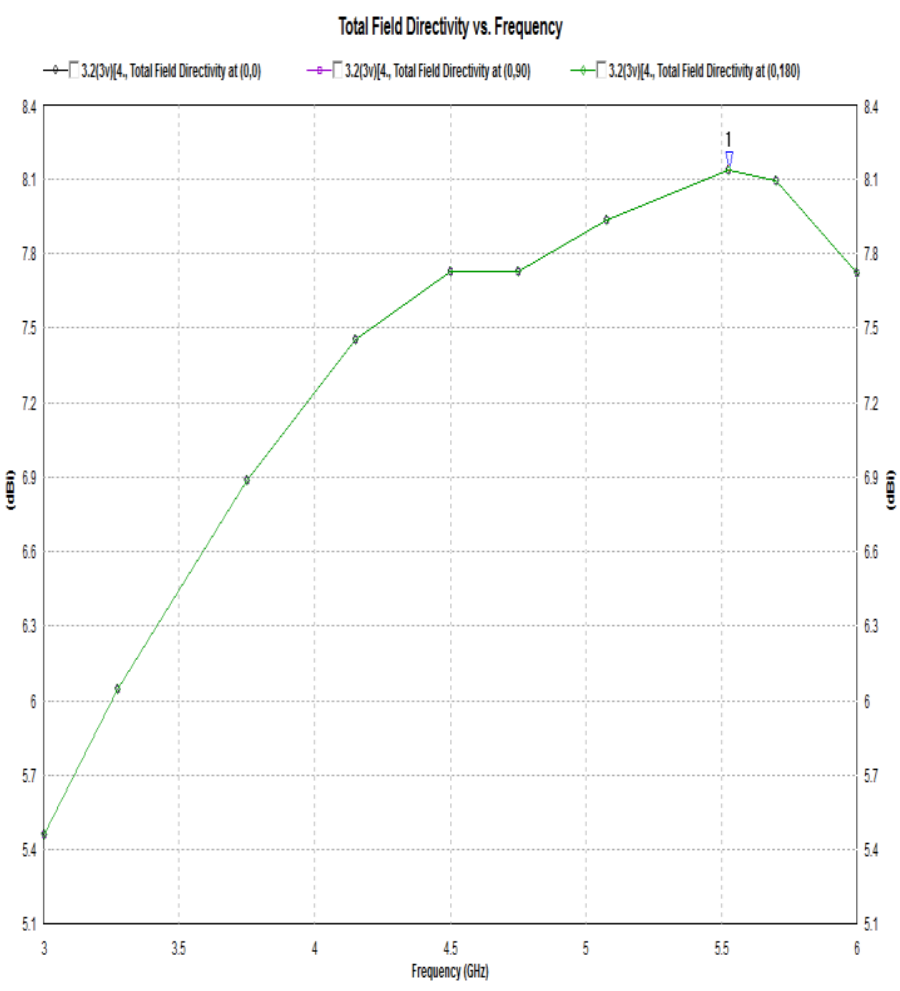

Fig -7: Total field Directivity v/s Frequency

Directivity $=8.135 \mathrm{dBi}$ at $5.52 \mathrm{GHz}$ 


\subsection{Radiation Pattern}

The 2D elevation and azimuth angle pattern for the antenna are shown below in Fig- 8 and Fig- 9 .
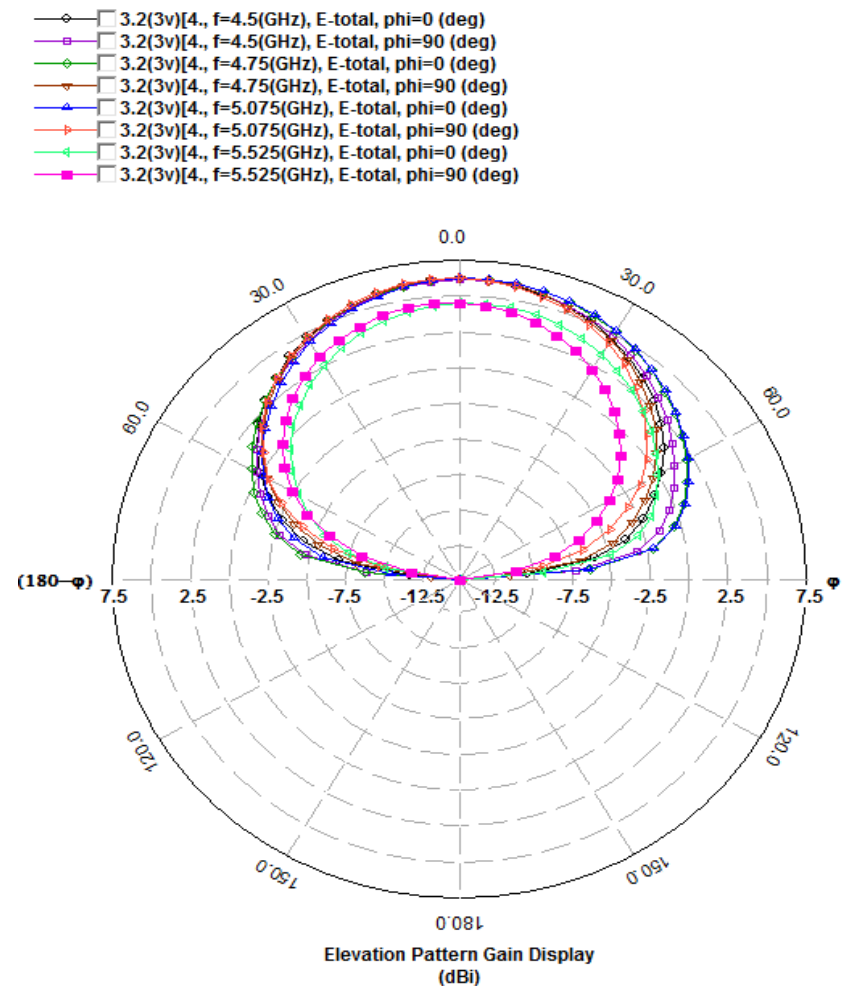

Fig -8: Elevation Pattern
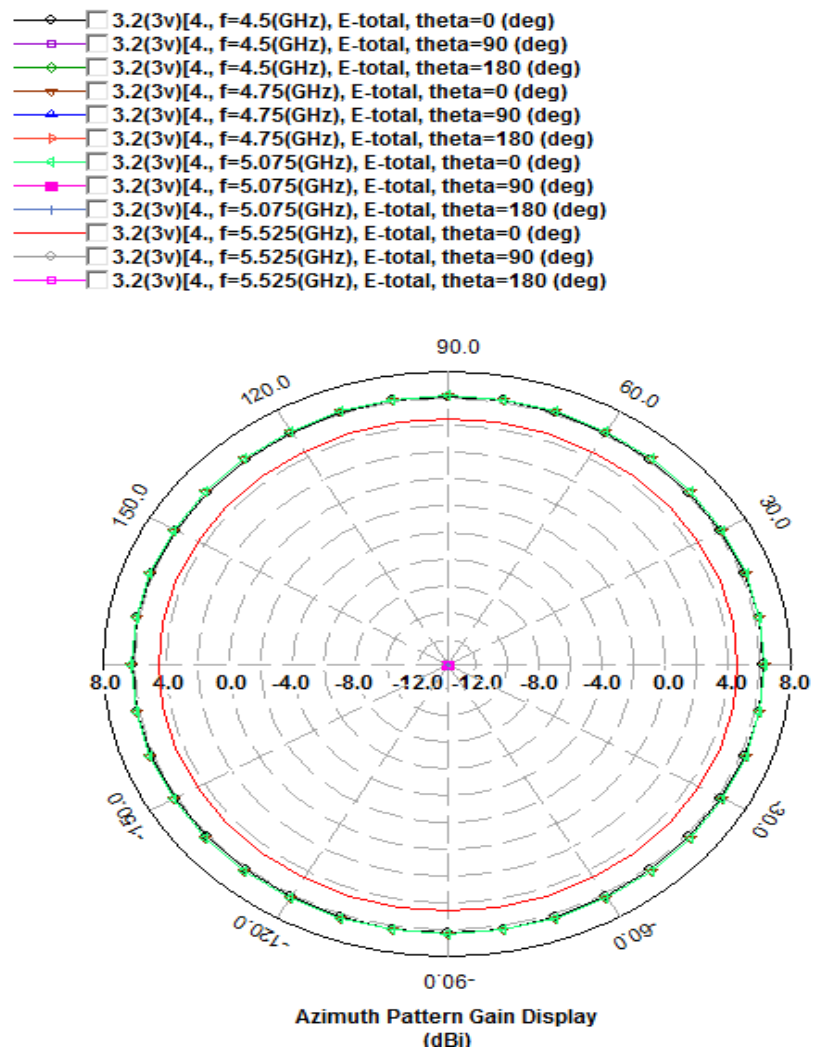

Fig -9: Azimuth Pattern

\subsection{Antenna Efficiency and Radiation Efficiency}

The antenna and radiation efficiency are shown below in Fig- 10.

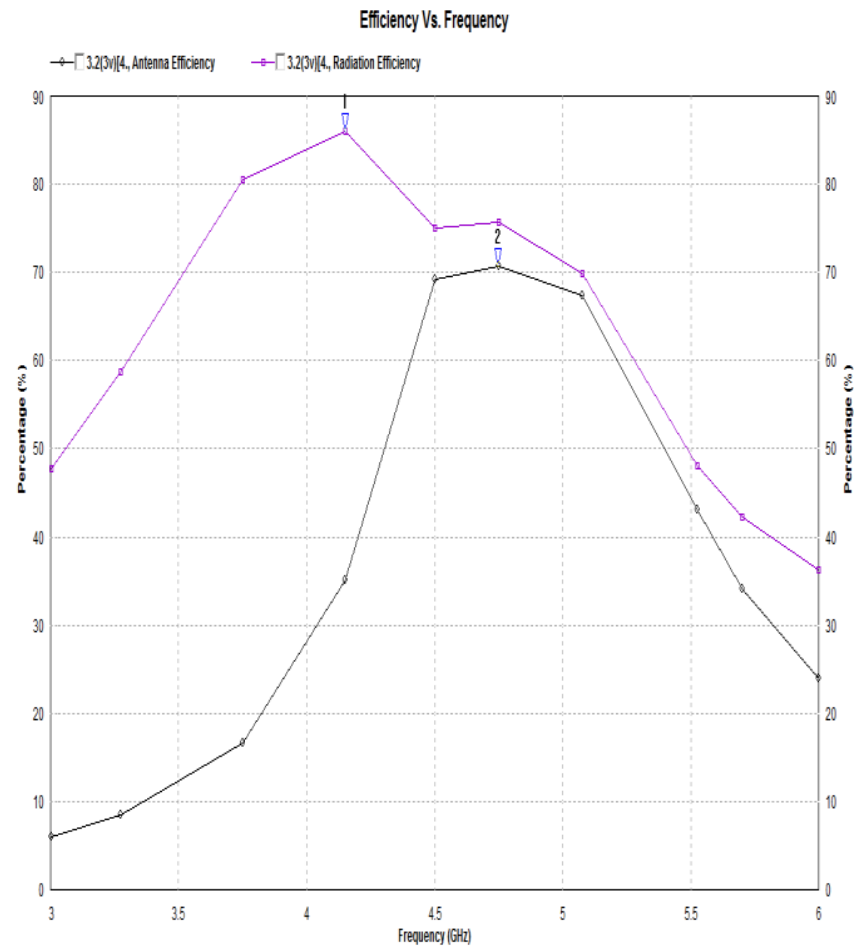

Fig -10: Efficiency v/s Frequency

Antenna efficiency $=70.65 \%$ at $4.74 \mathrm{GHz}$

Radiation efficiency $=85.87 \%$ at $4.14 \mathrm{GHz}$.

\section{CONCLUSION}

The design of V-slotted rectangular microstrip patch antennas can be widely used in WLAN and WiMAX applications. The $\mathrm{V}$-slot microstrip patch antenna is provided with a co-axial feed, the results are justified by simulating using IE3D simulator. The optimized antenna parameter results show that the antenna yields an axial ratio of 4.76 $\mathrm{dBi}$ at $4.74 \mathrm{GHz}$, VSWR 1.22 at $4.6 \mathrm{GHz}$ and 1.22 at 5.2GHZ. Return loss of about $-20 \mathrm{~dB}$ at $4.6 \mathrm{GHz}$ and $-20 \mathrm{~dB}$ at $5.2 \mathrm{GHz}$ was observed.The antenna has a bandwith of $1.04 \mathrm{GHz}$ and gain of $6.22 \mathrm{dBi}$ at $4.74 \mathrm{GHz}$. Antenna efficiency was observed to be $70.65 \%$ at $4.74 \mathrm{GHz}$ while the radiation efficiency was observed to be $85.87 \%$ at 4.14 $\mathrm{GHz}$.

\section{ACKNOWLEDGEMENT}

The Authors would like to thank Assistant Prof. Tazeen Shaikh, Prof. Vaishali Kulkarni HOD of Electronics and Tele-Communication Department and Dean Dr. Sharad Y. Mhaiskar of MPSTME (NMIMS), Mumbai for their support and encouragements, and for given testing and development facility for this work. 


\section{REFERENCES}

[1]. Neha Parmar, Manish Saxena, Krishnkant Nayak, "Review of Microstrip Patch Antenna for WLAN and WiMAX Application", Int. Journal of Engineering Research and Applications, Vol. 4, Issue 1(Version 1), January 2014. [2]. Pradeep Kumar, Neha Thakur, Aman Sanghi, "Micro strip Patch Antenna for 2.4 GHZ Wireless Applications", International Journal of Engineering Trends and Technology (IJETT), Volume 4 Issue 8, August 2013.

[3]. C. A Balanis, "Antenna Theory Analysis and Design", Wiley, 2nd edition, chapter 14. 1997.

[4]. David M.Pozar, "Microwave Engineering", 3rd edition, Wiley international edition, 2005.

[5]. P.Naveen Kumar, K.M.Vijay, T.Srinivas, K.Jagadeesh Babu, "A Modified Back to Back E-Shaped Patch Antenna for 4G MIMO Communications", International Journal of Engineering and Technology, Volume 2 No. 3, March, 2012.

[6]. Kumar, G. and K. P. Ray, "Broadband Microstrip Antennas", Artech House, USA, 2003.

[7]. Deshmukh, A. A. and G. Kumar, "Broadband and compact V- slot loaded RMSAs", Electronics Letters, Vol. 42, No. 17, 951-952, Aug. 17, 2006.

[8]. Deshmukh, A. A. and G. Kumar, "Compact broadband U-slot loaded rectangular microstrip antennas", Microwave \& Optical Technology Letters, Vol. 46, No. 6, 556-559, 2005.

[9]. Wong, K. L, "Compact and Broadband Microstrip Antennas”, John Wiley \& Sons, Inc, New York, USA, 2002. [10]. Tanawat Pantui, Chatchai Suphapitaksakul , Noppin Anantrasirichai, "A Wideband Dual V shape Slot Microstrip Antenna for Wireless Applications",International Symposium on Antennas and Propagation (ISAP 2009), October 20-23, 2009. 